\title{
Cytotoxicity of the saponin TTB2 on Ewing sarcoma cells
}

\author{
WENFENG HUANG and KUN ZOU \\ Hubei Key Laboratory of Natural Products Research and Development, Medical College, \\ China Three Gorges University, Yichang, Hubei 443002, P.R. China
}

Received February 23, 2014; Accepted August 14, 2014

DOI: $10.3892 /$ etm.2015.2544

\begin{abstract}
The steroidal saponin TTB2 can be isolated from the $n$-BuOH extracts of Trillium tschonoskii Maxim. The aim of the present study was to observe whether this saponin exerted any cytotoxic effects on malignant sarcoma cells, and to further investigate the possible underlying molecular mechanisms. The cell viability, cell cycle arrest and phosphorylation of certain important signal molecules in the sarcoma cell line were investigated. It was found that TTB2 inhibited the growth of the Ewing sarcoma cell line and arrested cells in the $G_{2} / M$ and $\mathrm{S}$ phases of the cell cycle in a dose- and time-dependent manner. Furthermore, the phosphorylation of extracellular signal-regulated kinase was inhibited by TTB2. In conclusion, the results showed that the saponin TTB2 isolated from T. tschonoskii Maxim exerts anticancer effects and may be a potential candidate for the development of anticancer drugs for use in the treatment of cancer.
\end{abstract}

\section{Introduction}

The efficacy of chemotherapeutic agents is largely dependent on their ability to inhibit the growth of tumor cells (1). A number of studies have demonstrated that certain phytochemicals present in medicinal herbs exert antitumor activity by inhibiting cancer cell growth (2). Trillium tschonoskii Maxim, also known as 'a pearl on head', is predominantly distributed in mid-Western China and has been used in traditional remedies for the treatment of headache, hypertension, neurasthenia, giddiness and cancer, as well as for the removal of carbuncles and the amelioration of pain, for $\geq 1,000$ years $(3,4)$. Previous studies have shown that a number of bioactive components, such as steroidal saponins and glycosides, can be found in species of the Trillium genus, including $T$. erectum $(5,6)$, T. kamtschaticum $(7,8)$ and T.tschonoskii Maxim (9). Saponins

Correspondence to: Professor Kun Zou, Hubei Key Laboratory of Natural Products Research and Development, Medical College, China Three Gorges University, 8 Daxue Road, Yichang, Hubei 443002, P.R. China

E-mail: xyyxy1999@aliyun.com

Key words: steroidal saponin, anticancer, cell cycle, extracellular signal-regulated kinase, chemotherapy are identified by their structures which contain a steroidal or triterpenoid aglycone and one or more sugar chains (10). Previous studies have elucidated that the biological and pharmacological properties of saponins are associated with their structural diversity. These are exploited in a number of traditional and industrial applications $(11,12)$. TTB2 is one of the steroidal saponins isolated from T. tschonoskii Maxim (9); its pharmacological effects and mechanisms remain unclear. The aim of the present study was to evaluate the bioactive effect of TTB2 on Ewing sarcoma (Rh1) cells.

\section{Materials and methods}

Reagents. Trypan blue, propidium iodide (PI) and RNase were purchased from Sigma-Aldrich (St. Louis, MO, USA). RPMI-1640 culture media and fetal bovine serum (FBS) were supplied by Gibco-BRL (Grand Island, NY, USA). Mouse polyclonal anti-phosphorylated-(p-)ERK and anti-ERK, and rabbit polyclonal anti-phosphorylated-(p-) AKT and anti-AKT were purchased from Cell Signaling Technology, Inc. (Danvers, MA, USA). Rabbit polyclonal anti- $\beta$-tubulin antibody and horseradish peroxidase-labeled secondary anti-mouse and anti-rabbit antibodies were purchased from Santa Cruz Biotechnology, Inc. (Santa Cruz, CA, USA). Other chemicals used in this study were special grade commercial products. This study was approved by the Medicine Scientific Research Ethics Committee of China Three Gorges University (Yichang, China).

Plant material and extraction and isolation of TTB2. The rhizomes of $T$. tschonoskii Maxim were purchased from Muyu, a town of the Shennongjia Forest District of Hubei (China). Professor Chen Faju, a botanist at the China Three Gorges University (Yichang, China), identified the nature of the collected T. tschonoskii Maxim. A voucher specimen (no. 2005ZW03128) was deposited in the Medicinal Plants Herbarium of the College of Chemistry and Life Science (China Three Gorges University). Air-dried powdered rhizomes $(6.4 \mathrm{~kg})$ were extracted with methanol under reflux. The methanol extract $(2,427 \mathrm{~g})$ was obtained. The extract was suspended in water (2.2 liters), and then extracted with $\mathrm{CHCl}_{3}$, EtOAc and $n$-BuOH successively. A portion of the $n$ - $\mathrm{BuOH}$ extract (775 g) was reduced in vacuo and dissolved in water to a volume small enough to allow the drug to dissolve, and then subjected to macroporous resin column chromatography (Guangfu Fine Chemical Research Institute, Tianjin, China) in 
elution with gradient solvents ( $100 \%$ water $\rightarrow 100 \%$ methanol). A portion of $80 \%$ methanol eluates $(2.0 \mathrm{~g})$ was separated by repeated reversed-phase $\mathrm{C}_{18}$ silica gel column chromatography (Guangfu Fine Chemical Research Institute) in elution with a gradient solvent system (acetonitrile:water, between 35:65 and 0:100) to give rise to 50 fractions. Fraction 37 (182 mg) was further separated by semi-preparative high-performance liquid chromatography eluted with $43 \%$ acetonitrile (within $30 \mathrm{~min}$, $2.0 \mathrm{ml} / \mathrm{min}$, detection at $203 \mathrm{~nm}$ ), giving rise to the compound TTB2 (32 mg). TTB2 powder was dissolved in distilled water. The filtered TTB2 stock solution was separated into individual aliquots, which were kept at $-20^{\circ} \mathrm{C}$ until further use.

Cell culture. Rh1 cells (St. Jude Children's Research Hospital, Memphis, TN, USA) were grown in antibiotic-free RPMI-1640 medium supplemented with $10 \% \mathrm{FBS}$ at $37^{\circ} \mathrm{C}$ and $5 \% \mathrm{CO}_{2}$.

Cell viability assays. The viability of the cells was determined using the trypan blue dye exclusion assay, in which the color changes reflected the dead cells (13). In brief, the cells $\left(1 \times 10^{4} / \mathrm{ml}\right)$ were first seeded in the cell culture flask (each concentration in triplicate). After $12 \mathrm{~h}$, the cells were treated with different concentrations of TTB2 $(5,7.5,10$, 12.5 and $15 \mu \mathrm{M}$ ) in medium for 12,24 and $48 \mathrm{~h}$, respectively. Following trypsinization, the cells exposed to $0.2 \%$ trypan blue were counted in an auto-hemocytometer (Invitrogen Life Technologies, Carlsbad, CA, USA). Each experiment was repeated at least three times.

Cell cycle analysis. Cancer cells $\left(5 \times 10^{6}\right)$ were treated with TTB2 at the indicated concentrations $(5$ and $10 \mu \mathrm{M})$ for $24 \mathrm{~h}$. The attached cells were then trypsinized and washed once with phosphate-buffered saline (PBS). The cells were resuspended in $2 \mathrm{ml} 70 \%$ ice-cold ethanol solution and fixed at $4^{\circ} \mathrm{C}$ overnight. The cells were centrifuged $(500 \mathrm{x} \mathrm{g}$ for $10 \mathrm{~min})$ to remove ethanol and washed again with PBS; the pellets were resuspended in $100 \mathrm{mg} / \mathrm{ml} \mathrm{PI} \mathrm{solution} \mathrm{containing} 100 \mathrm{mg} / \mathrm{ml}$ RNase, and then incubated at $37^{\circ} \mathrm{C}$ for $\geq 30 \mathrm{~min}$. The stained cells were analyzed for DNA content by flow cytometry (FCM; Beckman Coulter, Miami, FL, USA).

Western blot analysis. Protein expression was determined by western blot analysis. Briefly, Rh1 cells $\left(2 \times 10^{5}\right)$ were seeded in six-well plates for $12 \mathrm{~h}$ and then treated with the indicated concentrations of TTB2 for $24 \mathrm{~h}$. Following separation by SDS-PAGE, the proteins were transferred to polyvinylidene difluoride membranes and subjected to immunoblotting with antibodies against p-ERK, ERK, p-Akt [serine (Ser)473], Akt and tubulin at $4^{\circ} \mathrm{C}$ overnight. Subsequent to washing with $5 \%$ skimmed milk in tris-buffered saline and Tween 20 (TBST) buffer $(5 \mathrm{mM}$ Tris- $\mathrm{HCl}, \mathrm{pH} 7.6,136 \mathrm{mM} \mathrm{NaCl}$ and $0.05 \%$ Tween-20), the membranes were incubated with horseradish peroxidase-conjugated secondary antibodies and visualized using the enhanced chemiluminescence system (Pierce, Rockford, IL, USA).

Statistical analysis. The data are expressed as the mean \pm standard deviation. Statistical evaluations were performed using SPSS 10.0 software (SPSS Inc., Chicago, IL, USA) using
A

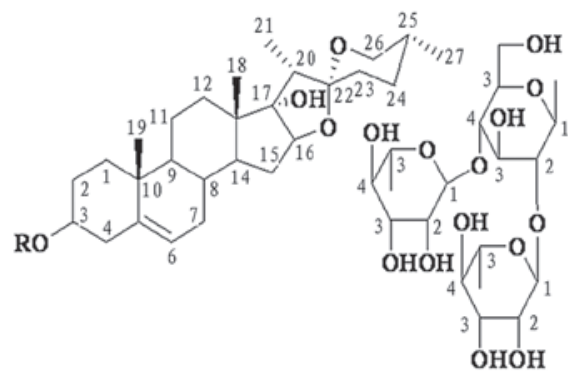

$\mathbf{R}$

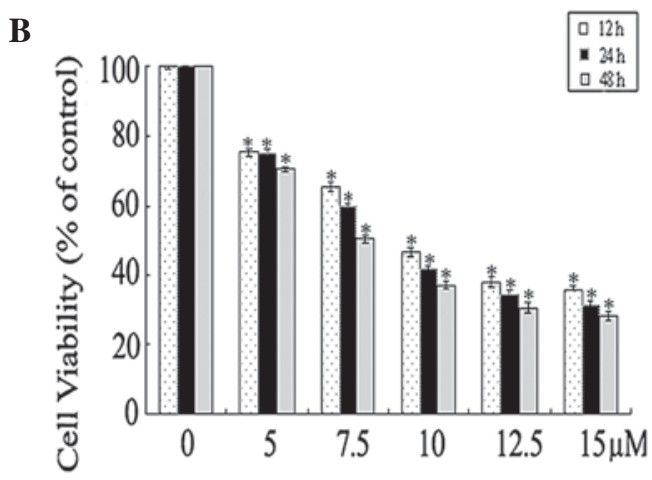

Figure 1. Chemical structure of TTB2 and its inhibition of Rh1 cell growth (A) TTB2 is pennogenin 3-O- $\alpha$-L-rhamnopyranosyl- $(1 \rightarrow 2)$ [ $\alpha$-L-rhamnopyranosyl-(1־4)]- $\beta$-D-glucopyranoside (molecular weight, 884.48). (B) Cells were incubated with different concentrations of TTB2 for 12,24 or $48 \mathrm{~h}$ separately. Inhibition of TTB2 on Rh1 cell growth was dose-dependent, which was determined by the trypan blue assay. Each value represents the mean \pm standard deviation of three replicates. ${ }^{*} \mathrm{P}<0.05$ vs. the control (untreated cells).

one-way analysis of variance. $\mathrm{P}<0.05$ was considered to indicate a statistically significant difference.

\section{Results}

Chemical structure of TTB2. As shown in Fig. 1A, the structure of TTB2 was pennogenin 3-O- $\alpha$-L-rhamnopyranosyl- $(1 \rightarrow 2)$ [ $\alpha$-L-rhamnopyranosyl- $(1 \rightarrow 4)]-\beta$-D-glucopyranoside.

Inhibition of Rh1 cell line viability by TTB2. The effect of TTB 2 on cell viability was examined by treating the Rh1 cells with five concentrations of TTB2 $(5,7.5,10,12.5$ and $15 \mu \mathrm{M})$ in the presence of $10 \%$ serum medium. After 12, 24 and $48 \mathrm{~h}$ of treatment, the viability of the cells was determined by the trypan blue assay. Untreated cells (control) were considered as the baseline (100\% viable) for the analysis. Fig. 1B shows that TTB2 appeared to be an effective inhibitor of Rh1 cell viability, which was inhibited in a dose- and time-dependent manner.

TTB2 induces $G_{2} / M$ and $S$ phase cell cycle arrest. To determine the effect of TTB2 on the cell cycle progression of Rh1 cells, FCM analysis was performed on cells treated with 5 and $10 \mu \mathrm{M}$ TTB2 for $24 \mathrm{~h}$ (Fig. 2). The two concentrations of TTB2 caused a significant increase in the percentage of $\mathrm{G}_{2} / \mathrm{M}$ phase cells (Fig. 2B and C), showing that TTB2 arrests the cell cycle progression in the $\mathrm{G}_{2} / \mathrm{M}$ phase when compared with the controls (Fig. 2A). The high concentration of TTB2 $(10 \mu \mathrm{M})$ 
A

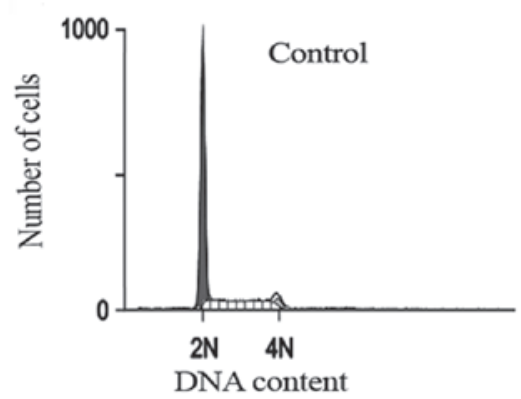

C

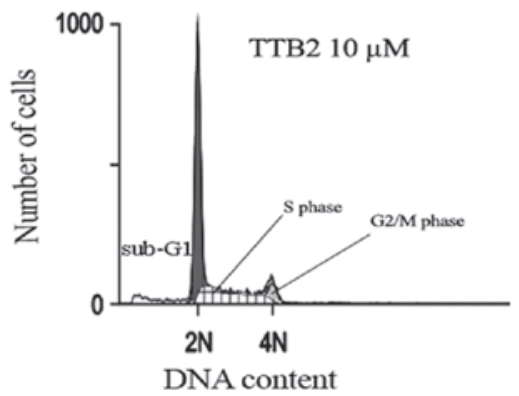

B

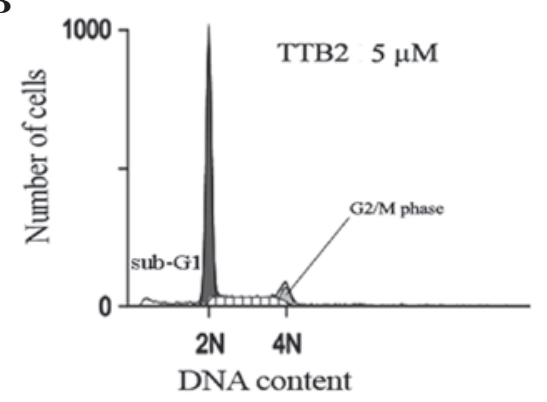

D

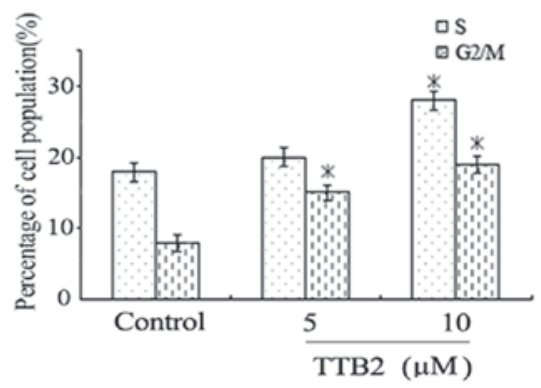

Figure 2. Cell cycle analysis as measured by FCM. Following treatment with the indicated concentrations of TTB2 for $24 \mathrm{~h}$, Rh1 cells were stained with the propidium iodide probe. (A-C) One of three independent FCM results showing the effects of (A) no treatment (control), (B) $5 \mu \mathrm{m} \mathrm{TTB2}$ and (C) $10 \mu \mathrm{m} \mathrm{TTB2}$ on the cell cycle phase. (D) The percentage of cells in $\mathrm{G}_{2} / \mathrm{M}$ and/or $\mathrm{S}$ phases increased among the Rh1 cells treated with TTB2 in a dose-dependent manner. ${ }^{*} \mathrm{P}<0.05$ vs. the control. FCM, flow cytometry. $2 \mathrm{~N}, \mathrm{Go} / \mathrm{G} 1$ phrase; $4 \mathrm{~N}, \mathrm{G}_{2} / \mathrm{M}$ phrase.

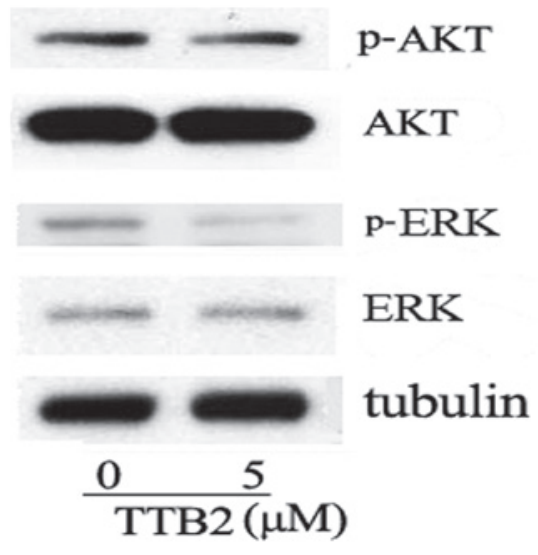

Figure 3. ERK signaling is involved in TTB2-induced apoptosis. The cells were treated with $5 \mu \mathrm{M}$ TTB2 for $24 \mathrm{~h}$ and the cell lysates were subjected to western blot analysis. TTB2 did not affect the phosphorylation of Akt; however, it inhibited the phosphorylation of ERK. ERK, extracellular signal-regulated kinase; p-, phosphorylated-.

also led to arrest in the $\mathrm{S}$ phase. These results indicate that TTB2 mediated a prolongation of cell cycle progression in the $\mathrm{G}_{2} / \mathrm{M}$ and $\mathrm{S}$ phases.

TTB2 inhibits the phosphorylation of ERK. It has been widely reported that activation of Akt or ERK exists in cancer cells (14). In the present results, TTB2 did not inhibit the phosphorylation of Akt (Ser473). However, TTB2 was found to modulate the activity of ERK, a member of the mitogen-activated protein kinase family. As shown in Fig. 3, following TTB2 treatment the phosphorylation of ERK was significantly decreased.

\section{Discussion}

With an increasing cancer rate worldwide, there is an urgent requirement for improvements in the therapeutic activity and selectivity of anticancer agents. Steroidal saponins are widely distributed in plants and exhibit pharmacological functions and biological activities $(12,15)$. The compound TTB2, pennogenin 3-O- $\alpha$-L-rhamnopyranosyl- $(1 \rightarrow 2)$ [ $\alpha$-L-rhamnopyranosyl$(1 \rightarrow 4)]-\beta-D$-glucopyranoside, is a steroidal saponin that has been isolated from T. kamtschaticum (8) and Paris polyphylla var. yunnanensis (16). However, few studies have focused on its bioactivity and the associated mechanisms. It has been reported that certain pennogenin steroid analogues from other plants exhibit diverse bioactivity. For example, pennogenin 3-O- $\alpha$-L-rhamnopyranosyl- $(1 \rightarrow 2)$ [ $\alpha$-L-arabinofuranosyl$(1 \rightarrow 4)]-\beta$-D-glucopyranoside, which is extracted from $P$. polyphylla var. yunnanensis, has been shown to markedly inhibit gastric lesions induced by ethanol and indomethacin (17). Furthermore, certain analogues, such as pennogenin 3-O- $\alpha$-1-rhamnopyranosyl- $(1 \rightarrow 2)$ [ $\alpha$-1-rhamnopyranosyl$(1 \rightarrow 3)]-[6-O$-acetyl]- $\beta$-D-glucopyranoside from Dracaena (18), pennogenin-O-R-L-rhamnopyranosyl- $(1 \rightarrow 2)$ [R-L-rhamnopyranosyl- $(1 \rightarrow 3)]-\beta-D$-glucopyranoside from D. deisteliana (18) and pennogenin 3-O- $\alpha$-L-rhamnopyranosyl$(1 \rightarrow 2)-\beta$-D-glucopyranoside from $P$. vietnamensis (19), have been found to be cytotoxic to cancer cells. The present results showed that TTB2, the pennogenin steroid from T. tschonoskii Maxim, could inhibit the growth of one type of tumor of the mesenchymal tissue.

The $\mathrm{G}_{2} / \mathrm{M}$ and $\mathrm{S}$ phases are important checkpoints for DNA damage and are critical to cell cycle progression (20). The present results clearly indicated that TTB2 caused an increase in the percentage of cells in $\mathrm{G}_{2} / \mathrm{M}$ (low concentration) and/or $\mathrm{S}$ 
(high concentration) phase, which is one mechanism by which TTB2 exerts its anti-proliferative effect. Since Akt and ERK activation contributes to anti-apoptosis effects and cell growth, the activation of Akt or ERK plays an important role in the pathology of cancer $(21,22)$. In the present study, Akt and ERK phosphorylation was observed. Although the inhibition of Akt did not occur in TTB2-treated Rh1 cells, the inhibition of ERK could be induced by TTB2. The results indicate that the ERK pathway is involved in TTB2-induced Rh1 apoptosis.

In conclusion, the present data revealed that Rh1 cells are sensitive to growth inhibition by TTB2, which is associated with cell cycle arrest and the inhibition of ERK. Therefore, the results of this study indicate that TTB2 isolated from T. tschonoskii Maxim may be a potential candidate for the development of anticancer drugs for use in the treatment of cancer.

\section{Acknowledgements}

This study was financially supported by the National Natural Science Foundation of China (nos. 31070313 and 21272136), the Yichang Science and Technology Research and Development Project (no. A201230234) and the CTGU Talent Scientific Research Initial Foundation (no. KJ2012B063).

\section{References}

1. Mansilla S, Llovera L and Portugal J: Chemotherapeutic targeting of cell death pathways. Anticancer Agents Med Chem 12: 226-238, 2012.

2. Rasul A, Song R, Wei W, et al: Tubeimoside-1 inhibits growth via the induction of cell cycle arrest and apoptosis in human melanoma A375 cells. Bangladesh J Pharmacol 7: 150-156, 2012

3. Fu L (ed): China Plant Red Data Book: Rare and Endangered Plants. Vol 1. Science Press, Beijing, 1992.

4. Li Q, Xiao M, Guo L, et al: Genetic diversity and genetic structure of an endangered species, Trillium tschonoskii. Biochem Genet 43: 445-458, 2005.

5. Hayes PY, Lehmann R, Penman K, Kitching W and De Voss JJ: Steroidal saponins from the roots of Trillium erectum (Beth root). Phytochemistry 70: 105-113, 2009.

6. Yokosuka A and Mimaki Y: Steroidal glycosides from the underground parts of Trillium erectum and their cytotoxic activity. Phytochemistry 69: 2724-2730, 2008.

7. Ono M, Sugita F, Shigematsu S, et al: Three new steroid glycosides from the underground parts of Trillium kamtschaticum. Chem Pharm Bull (Tokyo) 55: 1093-1096, 2007.
8. Nohara T, Miyahara K and Kawasaki T: Steroid saponins and sapogenins of underground parts of Trillium kamtschaticum Pall. II. Pennogenin- and kryptogenin 3-O-glycosides and related compounds. Chem Pharm Bull (Tokyo) 23: 872-885, 1975.

9. Nohara T, Kumamoto F, Miyahara K and Kawasaki T: Steroid saponins of aerial parts of Paris tetraphylla A. Gray and of underground parts of Trillium tschonoskii Maxim. Chem Pharm Bull (Tokyo) 23: 1158-1160, 1975.

10. Osbourn A, Goss RJ and Field RA: The saponins: Polar isoprenoids with important and diverse biological activities. Nat Prod Rep 28: 1261-1268, 2011.

11. Fuchs H, Bachran D, Panjideh H, Schellmann N, Weng A, Melzig MF, Sutherland M and Bachran C: Saponins as tool for improved targeted tumor therapies. Curr Drug Targets 10: 140-151, 2009.

12. Yang SL, Liu XK, Wu H, Wang HB and Qing C: Steroidal saponins and cytoxicity of the wild edible vegetable-Smilacina atropurpurea. Steroids 74: 7-12, 2009.

13. Tyagi A, Bhatia N, Condon MS, Bosland MC, Agarwal C and Agarwal R: Antiproliferative and apoptotic effects of silibinin in rat prostate cancer cells. Prostate 53: 211-217, 2002.

14. De Luca A, Maiello MR, D'Alessio A, Pergameno $M$ and Normanno N: The RAS/RAF/MEK/ERK and the PI3K/AKT signalling pathways: role in cancer pathogenesis and implications for therapeutic approaches. Expert Opin Ther Targets 16: Suppl 2: S17-27, 2012.

15. Güçlü-Ustündağ O and Mazza G: Saponins: properties, applications and processing. Crit Rev Food Sci Nutr 47: 231-258, 2007.

16. Chen CX, Zhou J, Zhang YT and Zhao YY: Steroid saponins of aerial parts of Paris polyphylla var. yunnanensis. Acta Bot Yunnan 12: 323-329, 1990 (In Chinese).

17. Matsuda H, Pongpiriyadacha Y, Morikawa T, Kishi A, Kataoka S and Yoshikawa M: Protective effects of steroid saponins from Paris polyphylla var. yunnanensis on ethanol- or indomethacin-induced gastric mucosal lesions in rats: structural requirement for activity and mode of action. Bioorg Med Chem Lett 13: 1101-1106, 2003.

18. Kougan GB, Miyamoto T, Tanaka C, et al: Steroidal saponins from two species of Dracaena. J Nat Prod 73: 1266-1270, 2010.

19. Huang Y, Cui LJ, Wang Q and Ye WC: Separation and identification of active constituents of Paris vietnamensis. Yao Xue Xue Bao 41: 361-364, 2006 (In Chinese).

20. Zhou BB and Elledge SJ: The DNA damage response: putting checkpoints in perspective. Nature 408: 433-439, 2000.

21. Moelling K, Schad K, Bosse M, Zimmermann S and Schweneker M: Regulation of Raf-Akt Cross-talk. J Biol Chem 277: 31099-31106, 2002.

22. Roberts PJ and Der CJ: Targeting the Raf-MEK-ERK mitogen-activated protein kinase cascade for the treatment of cancer. Oncogene 26: 3291-3310, 2007. 